\title{
An examination of firms' strategic orientations, innovativeness and performance with large Korean companies
}

\author{
Sohyoun Synthia Shin \\ Department of Finance and Marketing, College of Business, \\ California State University, Chico, California, USA, and \\ Sungho Lee \\ Department and College of Business Administration, \\ University of Seoul, Seoul, South Korea
}

\begin{abstract}
Purpose - This paper aims to provide an examination of firms' strategic orientations, innovativeness and performance with large Korean companies.

Design/methodology/approach - The authors investigated the impacts of firms' major key strategic orientations (customer orientation [CO], competitor orientation [PO], technology orientation [TO] and internal/cost orientation [IO]) on firm innovativeness (INNO) and performance outcomes with large Korean companies.

Findings - The results of the analysis showed that $\mathrm{CO}$, PO and TO positively influence the innovativeness, which contributes to firm performance.

Originality/value - The authors provide some managerial implications on the multiple roles of strategic orientations on firm INNO and performances, along with limitations of this study and future research directions.
\end{abstract}

Keywords Firm innovativeness, Customer orientation, Competitor orientation,

Technology orientation, Internal/cost orientation, Performance outcomes of innovativeness

Paper type Research paper

\section{Introduction}

Firm innovativeness (hereafter, INNO) has been regarded as a critical component for the success of firms in many academic fields, such as marketing, strategic and

(C) Sohyoun Synthia Shin and Sungho Lee. Published in the Asia Pacific Journal of Innovation and Entrepreneurship. This article is published under the Creative Commons Attribution (CC BY 4.0) licence. Anyone may reproduce, distribute, translate and create derivative works of this article (for both commercial and non-commercial purposes), subject to full attribution to the original publication and authors. The full terms of this licence may be seen at: http:// creativecommons.org/licences/by/4.0/legalcode

This paper has not been submitted for publication elsewhere in any language. Earlier versions and ideas of this paper were presented at 2010 Summer Marketing Educators' Conference (USA) held by American Marketing Association and 2011 ICIM (International Conference on Innovation \& Management) held by Yamaguchi University in Japan.

Received 19September 2016 Revised 3October 2016 Accepted 4 October 2016 
APJIE

10,1

184

organizational management, international business, etc. (Hauser et al., 2006; Rubera and Kirca, 2012). It has been conceptualized in various ways, such as INNO inputs (i.e. efforts made toward innovation, e.g. R\&D expenditure and patents), INNO outputs (i.e. consequences of innovation activities, e.g. incremental and radical innovation products) and INNO culture (i.e. the firm's ability to constantly introduce new products) (Rubera and Kirca, 2012). We are interested in the INNO as culture (i.e. the process view of innovation) for multiple reasons. First, it was found that firm INNO culture is positively related to the organization's ultimate performance outcomes such as financial position (e.g. profits) and firm value more than the other INNO constructs (Hurley and Hult, 1998; Rubera and Kirca, 2012). Second, it has been less examined in terms of its important drivers and consequences. Last, we are interested in the firm's strategic issues of the higher-order level. Likewise, the stream of INNO research found the importance of and called for further examination of corporate culture in driving INNO and its performance outcomes (Hauser et al., 2006; Shane and Ulrich, 2004; Tellis et al., 2009; Walker, 2004).

Accordingly, quite a few studies examined the impacts of firms' cultural constructs on INNO and/or its consequences (Atuahene-Gima, 1996; Calantone et al., 2002; Damanpour, 1991; Han et al., 1998; Hult et al., 2004; Hult et al., 2001; Hurley and Hult, 1998; Menguç and Auh, 2006; Noble et al., 2002; Rhee et al., 2010; Tajeddini et al., 2006; Zhou et al., 2005). Although the previous research findings are interesting and useful, we identified three research needs which warrant further exploration. First, we need to delineate and test the systematic and hierarchical relationships among firms' strategic orientations and INNO, as a few studies dealt with INNO culture as just one of organizational cultures, such as market orientation and learning orientation, at the identical level of strategic orientations (Hult et al., 2004; Hult and Ketchen, 2001; Menguç and Auh, 2006). Indeed, we acknowledge that many other studies logically conceptualized and tested the layered structure of relationships such that firms' more abstract strategic orientations, such as market orientation, technology orientation (TO), learning orientation and entrepreneurial orientation, influence INNO culture. Cumulative research evidence implies that firms' more generic cultural orientations drive INNO culture, which is oriented to the more specific task of new product development and introduction (Damanpour, 1991; Woodside, 2005). Second, many studies, based on the selection logic of self-interests, examined market orientation most frequently and then learning and entrepreneurial orientations as the firm's more abstract drivers of INNO, whereas about two studies comprehensively investigated the influence of firms' alternative strategic orientations on INNO (Noble et al., 2002; Zhou et al., 2005). This suggests the need to explore firms' alternative strategic orientations, as inclusively as possible, as the drivers of INNO. Last, majority of studies have been done in Western countries, even presenting the possibility of a stronger positive relationship between INNO and its performance outcomes in Western countries than in non-Western countries, although this prediction was not empirically confirmed (Rubera and Kirca, 2012). Compatible with the empirical finding of no difference between Western and Eastern countries, a recent study showed that the effects of firms' strategic orientations on innovations are quite strong in the context of Chinese companies. This implies that the stronger impact postulated in Western countries may not be warranted, i.e. just the biased expectation based on the huge number of studies or "pure guessing" (Zhou et al., 2005). Please keep in mind, though, that Zhou et al. (2005) examined INNO outputs, not INNO culture, as the specific construct of INNO. 
The aforementioned points suggest the need and direction of our research. Specifically, we argue the need of the study which examines the following elements affecting a company's performance:

- The systematic and hierarchical relationships among firms' strategic orientations and INNO may well be studied.

- It is meaningful to investigate firms' alternative strategic orientations, as comprehensively as possible, as the drivers of INNO.

- It would be necessary to examine the effects of firms' strategic orientations on INNO in Eastern countries.

Hence, the major question addressed in our study is whether each of key strategic orientations, such as customer orientation (hereafter, $\mathrm{CO}$ ), competitor orientation (hereafter, PO), TO and internal/cost orientation (hereafter, IO), is related to INNO culture and firm performance in an Eastern country such as Korea.

$\mathrm{CO}$, as an important component of market orientation, is "the sufficient understanding of one's target buyers to be able to create superior value for them continuously" (Narver and Slater, 1990, p. 10). As the other important components of market orientation, $\mathrm{PO}$ means that:

[...] a seller understands the short-term strengths and weaknesses and long-term capabilities and strategies of both the key current and the key potential competitors (Narver and Slater, 1990, pp. 10-11).

TO refers to the firm's:

[...] ability and will to acquire a substantial technological background and use it in the development of new products [...] it also means that the company can use its technical knowledge to build a new technical solution to answer and meet new needs of the users (Gatignon and Xuereb, 1997, p. 78).

IO means "the firm's pursuit of efficiency in all parts of its value chain [...] pursuit of operational excellence" (Olson et al., 2005, p. 53), and it also refers to the extent that the business emphasizes on the activities such as "pursuing operating efficiencies, cost advantages in raw material procurement, and economies of scale" (Homburg et al., 1999, p. 15). In other words, regarding the choice of the firm's specific strategic orientations, we relied on previous studies and the firm's generic competitive strategy alternatives. Specifically, CO, PO and TO may pass through INNO to performance in the route of differentiation strategy, whereas IO may lead to outcome in the route of cost leadership strategy, which may or may not be related to INNO (Day, 1994; Gatignon and Xuereb, 1997; Jaworski and Kohli, 1993; Narver and Slater, 1990; Lukas and Ferrell, 2000; Porter, 1985). Further, considering that these strategic orientations are not mutually exclusive and it is plausible for firms to engage in multiple strategic-oriented behaviors simultaneously (Day and Nedungadi, 1994; Gatignon and Xuereb, 1997; Slater and Narver, 1998), it would be meaningful to examine the driver roles of these strategic orientations in influencing firm INNO culture and its performance outcomes.

The findings of this study may not only add to the research stream of INNO but also help management to better understand what types of strategic orientations may well be cultivated for improving the firm's INNO culture, which ultimately results in firm consequences such as customer satisfaction (CS) and profitability. The remainder of the 
APJIE

10,1

\section{6}

paper is organized as follows. First, we propose our conceptual model and the hypotheses on the relationships among our focal constructs of interest, i.e. the relationships of key strategic orientations with INNO and the relationships of INNO with firm performances. Second, the research method, the data characteristics and the analyses and results are presented. We conclude by discussing the implications of our findings along with the limitations and future research directions.

\section{Conceptualization and hypotheses}

We start by presenting the result of our conceptualization in advance and then explain our reasoning behind the hypotheses. Figure 1 summarizes our research model. We propose the relationships among four different strategic orientations and INNO with three definite directional associations. More specifically, we derive and test the layered relationships among strategic antecedents, INNO and firms' performance outcomes, such as CS, market adaptability (ADAPT) and firm profitability.

\subsection{Firms' strategic orientations and innovativeness}

Strategic orientation reflects the strategic directions implemented by a firm to guide its proper activities for continuous superior performance (Gatignon and Xuereb, 1997; Noble et al., 2002; Zhou et al., 2005). Viable strategic orientations include market orientation (Kohli and Jaworski, 1990; Narver and Slater, 1990) and TO (Gatignon and Xuereb, 1997; Noble et al., 2002; Zhou et al., 2005). More recent research indicates that three components of market orientation, $\mathrm{CO}$, PO and interfunctional coordination (Narver and Slater, 1990), behave differently and should be treated as distinct constructs (Gatignon and Xuereb, 1997; Lukas and Ferrell, 2000). In addition, the research stream on the huge body of market orientation studies generally deduces the agreement that constructs of market orientation had better be classified into market orientation as cultural constructs and market orientation as organizational behavioral constructs (Kirca et al., 2005). In other words, CO and PO are market orientation as cultural constructs (Narver and Slater, 1990), whereas generation and dissemination of response

Figure 1.

The research model

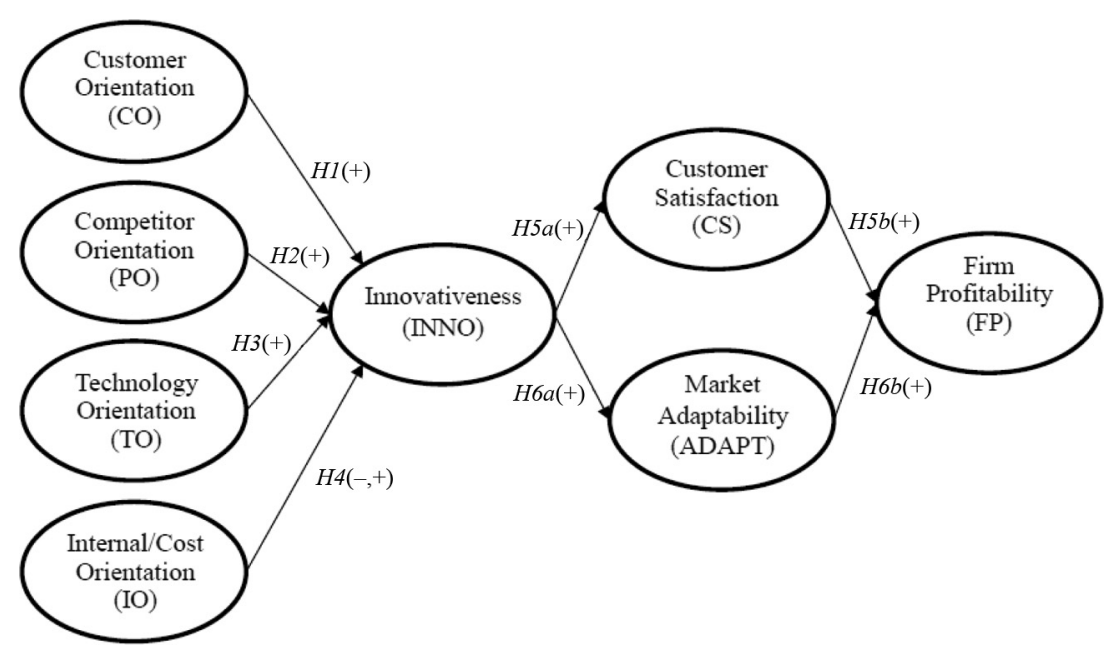


on market-based information and interfunctional coordination (Narver and Slater, 1990; Kohli and Jaworski, 1990) are market orientation as the firm's behavioral constructs (Day and Nedungadi, 1994; Kirca et al., 2005; Lee et al., 2006). Hence, it is desirable to examine the respective impacts of $\mathrm{CO}$ and $\mathrm{PO}$, as the firm's more abstract strategic orientations, on INNO. Last, IO has also been considered one type of viable strategic orientation that attempts to reduce costs in both primary and supportive activities for operational excellence (Porter, 1985; Treacy and Wiersema, 1993). Hence, the four types of strategic orientations represent the firm's relative emphasis on understanding and managing the environmental forces and may have differential effects on dimensions of firm performance (Voss and Voss, 2000). Specifically, CO, PO and TO may pass through INNO to performance in the route of differentiation strategy, whereas IO may lead to outcome in the route of cost leadership strategy, which may or may not be related to INNO (Day, 1994; Gatignon and Xuereb, 1997; Jaworski and Kohli, 1993; Narver and Slater, 1990; Lukas and Ferrell, 2000; Porter, 1985). Likewise, we want to examine whether these orientations have differential effects on the firm's INNO culture.

In the extant literature on innovation, innovation is construed to be sought, in various ways, with a new product/service, a new process, a new organizational structure or an administrative system (Rubera and Kirca, 2012). With this background in mind, the firm's INNO culture refers to a firm's receptivity and inclination to adopt new ideas that lead to the development and launch of new products (Hurley and Hult, 1998). In other words, the INNO culture represents the process view of innovation such that performance gains are brought about by specific competitive capabilities which go beyond developing and introducing new products; these capabilities are embedded in the cultural traits of innovative firms (Rubera and Kirca, 2012; Tellis et al., 2009). The INNO culture directly results in the firm's capacity to innovate, i.e. the capacity to introduce new products/services or idea in the organization (Damanpour, 1991; Hurley and Hult, 1998).

CO emphasizes on sufficient understanding of target customers so as to deliver superior values for them. Thus, customer-oriented firms show continuous and proactive disposition toward meeting customers' expressed and latent needs (Han et al., 1998). When customer needs change rapidly, $\mathrm{CO}$ enables firms to recognize those changes and guides them to invest necessary resources in developing appropriate new products/services, refining production processes and offering a flexible product line to cater to customers' changing preferences (Slater and Narver, 1998). As a result, customer-oriented firms can effectively adapt to market changes. Moreover, it is shown that $\mathrm{CO}$ increases the introduction of "new-to-the-world" products and reduces the launching of "me-too" products (Lukas and Ferrell, 2000).

However, a few concerns were manifested such that a "too much" focus on the salient needs of the consumer can have a detrimental effect on INNO when latent needs go unrecognized (Szymanski et al., 2007) or that a "too-much" focus on CO might reduce INNO (i.e. a special type of innovation, low-end disruption by Christensen and Bower, 1996). We reason, though, that these concerns may refer to a special, myopic view of $\mathrm{CO}$, which is incompatible with original conceptualization of $\mathrm{CO}$. In addition, majority of evidence suggests a positive relationship between $\mathrm{CO}$ and INNO (Atuahene-Gima, 1996; Han et al., 1998; Hult et al., 2004; Hurley and Hult, 1998; Noble et al., 2002; Rhee et al., 2010; Tajeddini et al., 2006; Zhou et al., 2005). Hence, we present our first hypothesis: 
APJIE

10,1

H1. Firm's CO is positively related to INNO.

Han et al. (1998) view INNO as one of the core value-creating capabilities that bridges the market orientation-performance relationship. Deshpande et al. (1993) speculated on a strong linkage between market orientation and INNO for achieving superior business performance outcomes. As a potent component constituting market orientation, $\mathrm{PO}$ focuses on understanding the strengths and weaknesses of existing and potential competitors (Narver and Slater, 1990). With a deep understanding of rivals, a firm can assess its position, determine appropriate strategies and respond quickly to competitors' actions by developing modified or newly enhanced products or processes (Gatignon and Xuereb, 1997). Moreover, Grinstein (2008) claimed that market orientation components positively affect innovation consequences, showing the positive effect of PO on INNO outputs even at the low level of $\mathrm{CO}$ in his meta-analysis.

On the other hand, Lukas and Ferrell (2000) argue that PO increases the introduction of "me-too" products and reduces the launching "new-to-the-world" products. This argument is interpreted by Szymanski et al. (2007) such that PO may have a detrimental effect on INNO when new products result from reactive rather than proactive strategies. However, reactive competitive strategic orientation may be likely to result in a low level of PO, because PO generally facilitates firms' capability to adapt to the changing environments. Further, the objective of competitor-centered approach is to keep pace with and/or remain ahead of competitors (Han et al., 1998). Accordingly, PO of modern firms helps firms to configure and reconfigure their resources to provide advanced customer values by exhibiting new products and services or enhanced processes (Grinstein, 2008). This reasoning is also consistent with majority of evidence on the positive relationship of PO and INNO (Atuahene-Gima, 1996; Han et al., 1998; Hult et al., 2004; Hurley and Hult, 1998; Noble et al., 2002; Rhee et al., 2010; Tajeddini et al., 2006; Zhou et al., 2005). Hence, we present our second hypothesis:

\section{H2. Firm's PO is positively related to INNO.}

TO holds that consumers prefer products and services with technological superiority, leading to the development of more innovative and technologically superior products compared to those offered by competitors (Gatignon and Xuereb, 1997). Prior research has identified that technology capability is important to new product development (Cooper and Kleinschmidt, 1994; Song and Parry, 1997) and product differentiation (Porter, 1985). Based on a meta-analysis of over 40 studies, Montoya-Weiss and Calantone (1994) find technical proficiency to be a critical factor in new product success. Such technological superiority gives firms the potential for greater competitive advantage which cannot be easily imitated by competition (Cooper, 1985; Gatignon and Xuereb, 1997; Song and Parry, 1997). Based on further empirical evidence on the positive relationship between TO and various constructs of INNO (Noble et al., 2002; Shane and Ulrich, 2004; Zhou et al., 2005), we deduce our third hypothesis:

\section{H3. Firm's TO is positively related to INNO.}

Internally oriented firms pursue efficiency in all processes of their value chain activities, i.e. low cost or cost leadership strategy (Porter, 1985). These organizations attempt to reduce costs not only in primary activities, such as logistics, operations and sales and 
marketing, but also in support activities, such as R\&D and administrative functions. In addition, Olson et al. (2005) claim that IO emphasizes on efficiency through standardized practices for low cost. Accordingly, firms with high level of IO are expected to rely on centralized decision-making and formal organization structures, ensuring that risk and administrative expenses are held to a minimum (Ruekert et al., 1985; Walker and Ruekert, 1987). Thus, firms of IO-embedded culture are expected to be reluctant to INNO, because INNO may cause high level of transformation and changes accompanied with enormous expenses.

On the other hand, internally oriented firms also pursue operational excellence that they can translate into higher sales through lower prices or higher margins, utilizing creative and new approaches to efficiency (Treacy and Wiersema, 1993). That is, internally oriented firms may well be motivated to search for innovative approach to efficiency. Moreover, the ambidexterity proposal in organization research suggests that INNO includes both exploration and exploitation (March, 1991). According to this proposal, exploration is the hallmark of firms with high INNO, whereas exploitation is that of internally oriented firms. Exploitation enables the firm to realize improvements as it drives down the learning curve, creating better outcomes (Alberts, 1989). This IO may result in better and newly enhanced outcome, i.e. one dimension of INNO: exploitation, leading to higher level of firm performance. Studies directly investigating the relationship between IO and INNO are rare, and we judge that the relationship of interest may be either positive or negative. Hence, we propose the fourth hypothesis as alternative hypotheses at this stage:

H4. Firm's IO is negatively related to INNO.

H4alternative. Firm's IO is positively related to INNO.

\subsection{Innovativeness and firm performance outcomes}

Firms with low INNO may invest time and resources in studying markets but can hardly translate this market study into practice. On the other hand, the high level of capacity to innovate is one of very important factors which positively impact firm performances (Hurley and Hult, 1998; Porter, 1990; Rubera and Kirca, 2012). The resource-based view explains how firms derive competitive advantages by channeling resources into the development of new products, processes and so forth (Wernerfelt, 1984). INNO is a means for changing an organization to achieve desired outcomes, whether it is pursued as a response to changes that occur in its external or internal environment or as a proactive move taken to influence an environment.

However, previous studies have shown mixed results on the relationship between INNO and the firm's performance outcomes (Abratt and Lombard, 1993; Henard and Szymanski, 2001; Poolton and Barclay, 1998). The conflicting findings imply that there may be potential influences of unexplored mediating or moderating constructs on the relationship between INNO and the firm's performances, which is neatly confirmed by a comprehensive and meticulous meta-analysis of firm INNO constructs and performance outcomes (Rubera and Kirca, 2012). Following the theoretical logic of Rubera and Kirca (2012), we want to test that CS and market ADAPT operate as key mediating variables in the route from INNO to financial performances (FPs).

It is reasoned that enhancement of FP resulting from INNO is brought about by the extent to which INNO substantively articulates values to customers. Relatedly, Agarwal 
APJIE

10,1

et al. (2003) found that the immediate impact of market orientation is to spur innovation which enhances judgmental performance (e.g. CS, service quality and employee satisfaction), which, in turn, enhances objective performance. Moreover, Hoover et al. (2001) make a similar claim. Therefore, it is posited that the firm's INNO is positively related to $\mathrm{CS}$.

Moreover, the high level of CS is widely believed to be the best indicator of a firm's future profit, and firms increasingly use CS as a criterion for diagnosing product and service performance (Anderson et al., 1994; Day and Wensley, 1988; Kaplan and Norton, 1996). In addition, Fornell (1992) and Anderson et al. (1994) proved that there are several key benefits of high CS, such as increased loyalty for current customers; reduced price elasticities; lower costs of future transactions and attracting new customers; and enhanced reputation for the firm. In addition, we have the evidence of empirical generalization on the relationship between CS and FP (Gruca and Rego, 2005; Morgan et al., 2006).

In sum, we present the following hypotheses, meaning that $\mathrm{CS}$ is expected to act as a mediator to FP from INNO:

H5a. Firm's INNO is positively related to CS.

H5b. Firm's CS is positively related to FP.

The creation of new products is a multidisciplinary process which demands the necessary involvement of different functional units (Olson et al., 2001). Although INNO is high, it may take a lot of time for INNO to be realized into firm profitability, because of coordinating a lot of conflicts among different functional units. Although it is difficult to judge the right timing of new product introduction, a fundamental principle indicates that firms' efforts toward innovation should be adaptive to the market requirements. Thus, to have positional advantage and improved FP requires timely adaptation of new products to the market demand. Accordingly, INNO may well be adaptive to the changes in the market needs, resulting in achieving market share relatively earlier and larger than competitors. This assertion is consistent with the marketing literature, indicating that successful firms are distinguished not only by well-conceived marketing capability such as new product development ability but also by their ability to actualize the success of new products/services in timely manners (Vorhies et al., 1999). Therefore, it is posited that the firm's INNO is positively related to market ADAPT (Rubera and Kirca, 2012).

ADAPT represents the ability of the firm to respond to changes in its environment (Ruekert et al., 1985). ADAPT is ultimately reflected in the market success of an organization's new products and/or services (Kaplan and Norton, 1996; Ruekert et al., 1985). Therefore, ADAPT is expected to successfully connect INNO with ultimate organizational consequence, FP, by transforming "intension" of INNO to "realization". This reasoning accordingly suggests that ADAPT is positively related to firms' profitability.

In sum, we present the following hypotheses, meaning that ADAPT is expected to act as a mediator to FP from INNO:

H6a. Firm's INNO is positively related to ADAPT.

$H 6 b$. Firm's ADAPT is positively related to FP. 


\section{The research method}

The location context of the study is the metropolitan area of Seoul, Korea. Given its global reputation as an advanced emerging country, we think that Seoul is a reasonable context in that it possesses unique mixtures of modern companies' orientations such as CO, PO, TO and IO. More importantly, as argued in the Introduction, it is very important to accumulate the empirical evidence on the antecedents and consequences of INNO in Eastern countries, given the sheer number of studies accomplished in Western countries. Compared to Zhou et al.'s (2005) analysis of Chinese companies and Rhee et al.'s (2010) inquiry of Korean small- and medium-sized companies, our study aims to test our hypotheses in the context of relatively large Korean companies, contributing to enhancing the generalizability of findings about the relationships among firms' strategic orientations, INNO and performances.

With this intention of improving generalizability, we collected the data from various sectors of commerce, including manufacturing and service industries, not to be idiosyncratic to any specific industry domain. Using a list of Korean top 500 firms in terms of sales, we developed a contact list of strategy and/or marketing department managers. Questionnaires were sent to key informants included in the contact list by email. Data collection occurred over six weeks and resulted in a usable sample of 98 . The response rate of 19.6 per cent was acceptable but rather low, so additional 79 questionnaires were collected from executive MBA students at one of the leading universities in Seoul, Korea. After discarding 5 unusable responses, in total, 177 respondents' responses were judged to be usable. Of the total responses, 104 (58.8 per cent) were answered by mail and the rest were collected by email. About 79 per cent of the respondents were general managers or higher-ranked managers, and 63.2 per cent are in the related functions such as marketing, strategy or planning. The average working year in the current organization was 7.57.

We compared the three types of responses to check the response/non-response biases: response medium: mail vs email; response time: first three weeks vs last three weeks; and response sources: from Korean top 500 company managers vs executive MBA students. The result showed that means of study variables did not differ significantly between mail- and email-based respondents. In addition, comparisons of early and late responders and those of data sources indicated no significant differences in means of the major constructs, leading us to conclude that the likelihood of non-response bias would be minimal (Armstrong and Overton, 1977). Consistent with related previous studies (Narver and Slater, 1990), the unit of analysis in our study is the respondent's "business unit", as it operates in its "principal served market".

\subsection{Measures}

$\mathrm{CO}, \mathrm{PO}$ and $\mathrm{TO}$ were all measured in the respective sets of four items. These measures were developed based on the original items of the previous studies (Gatignon and Xuereb, 1997; Narver and Slater, 1990). IO was measured in three items. The items were trimmed and used based on the previous studies (Homburg et al., 1999; Olson et al., 2005).

INNO was asked in four items. These four items were adopted from the previous study (Hurley and Hult, 1998). CS was measured by the four item scales which captured respondents' perceived assessments of satisfaction, using a synthesis of previous 

items. The original items of the previous studies were revised to be used (Morgan et al., 2003; Walker and Ruekert, 1987). FP was measured by the three item scales which referred to respondents' perceptions of profitability over the past 12 months (Morgan et al., 2002). Although our measure of FP is not objective, Naman and Slevin (1993) indicate that managers' subjective assessment of FP is consistent with objective performance. We measure all constructs in terms of a Likert-type scale, rating from 1 to 7 with the following equivalences ("1: strongly disagree"; "4: neutral"; and "7: strongly agree").

\subsection{Data purification and checking the common method bias}

Figure 1 illustrates the proposed latent variable model, showing all structural paths. Before testing this model, a series of tests were performed to establish the uni-dimensionality of the constructs. All constructs and FP were first-order constructs. The validity was initially assessed by examining the reliability of the constructs and the item-to-total correlations. Items of low item-to-total correlation and/or those items loaded into multiple constructs were deleted. Therefore, one item from INNO was eliminated because of cross-loading.

A Harman one-factor test serves to assess the potential for common method bias in the data (Podsakoff and Organ, 1986). After careful item purification, a factor analysis of the dependent and independent variables resulted in a solution that accounted for 72.2 per cent of the total variance, and the first factor accounted for 34.6 per cent of the variance, with total eight unrotated factors presented. Therefore, common method bias is not likely to be a concern.

In addition, the processes of data collection were very carefully designed. To prevent potential common method bias, we varied the medium of collecting data, i.e. paper-and-pencil survey and computer-aided questionnaires by email, as the single medium of data collection has frequently been argued as a strong potential cause of common method bias from the perspective of measurement context. Furthermore, we allowed the respondents' answers to be anonymous such that this procedure should reduce their evaluation apprehension and the tendency of being socially desirable, which are sources of common method effects (Podsakoff et al., 2003).

\section{Analyses and results}

\subsection{Basic analysis}

We used LISREL 8.50 to test the estimated measurement model. The results showed that our selected items provide good explanations for the respective constructs. A test of reliability, using Cronbach's coefficient alpha, showed that the alpha values of CS, ADAPT and FP exceeded Nunnally's (1978) standard of 0.70 (CS = 0.947; $\mathrm{ADAPT}=0.902 ; \mathrm{FP}=0.919 ; \mathrm{INNO}=0.767 ; \mathrm{CO}=0.890 ; \mathrm{PO}=0.813 ; \mathrm{IO}=0.822 ;$ and TO $=0.888$ ). Therefore, we established support for convergent validity with a high level of internal consistency (Bagozzi and Yi, 1988). We used the measured values for all constructs for the consistent level of the model analysis.

The overall fit of the model in Figure 1 was good. Also, $\chi^{2}$ was 616.01 with 336 degrees of freedom, and the CFI was 0.943 . In addition, other goodness of fit indices were also acceptable $(\mathrm{GFI}=0.880 ; \mathrm{NFI}=0.930 ; \mathrm{RMR}=0$ 0.120; $\mathrm{RMSEA}=0.069)$. All of these results confirmed that the data successfully fit the proposed model. 
In $H 1, H 2, H 3$ and $H 4$, we proposed the relationships among the firm's strategic orientations and INNO. The positive relationships between $\mathrm{CO}$ and INNO $(\beta=0.38, t=$ 4.83), between PO and INNO ( $\beta=0.35, t=3.64)$ and between TO and INNO $(\beta=0.28$, $t=3.32$ ) were identified. However, the relationship between IO and INNO was not found $(\beta=0.01, t=0.09)$. The possible reasons will be discussed later with future research directions in the Discussion and conclusion section.

In $H 5 a$ and $H 6 a$, the positive relationships were found between INNO and CS and between INNO and ADAPT. The effect of INNO on CS was $0.83(t=10.01)$ and that of INNO on ADAPT was $0.60(t=9.15)$. These results support $H 5 a$ and $H 6 a$. In $H 5 b$ and $H 6 b$, the relationships were identified between $\mathrm{CS}$ and $\mathrm{FP}$ and between ADAPT and FP ( $\beta=0.31, t=3.79$ for the effect of CS on FP; $\beta=0.52, t=6.00$ for the effect of ADAPT on FP). These results support $H 5 b$ and $H 6 b$.

The results of hypotheses analyses have also been presented with standard estimates and $t$-values of the respective hypothesized paths in Table I.

\subsection{Additional analyses}

To promote further understanding, we analyzed the total standardized effects of all the antecedent constructs on each of performance consequences: CS, ADAPT and FP (Figure 2). These additional analyses provide some interesting results.

Consistent with the analysis of hypotheses, the respective effects of $\mathrm{CO}, \mathrm{PO}$ and TO on CS are significant, but the effect of IO on CS is not significant. With ADAPT as a consequence variable, only $\mathrm{PO}$ and $\mathrm{TO}$ show significant direct relationships with ADAPT, yet the effect of $\mathrm{CO}$ on ADPT is not statistically significant. Thus, $\mathrm{CO}$ may be mediated by INNO to have an impact on ADPT. With FP as a consequence variable, CO and $\mathrm{TO}$ are related to $\mathrm{FP}$ in a positive way, but $\mathrm{PO}$ is not related to FP. That is, it is indicated that PO needs INNO to stretch to FP. These analyses imply that each of strategic orientations may have very different paths and mechanisms through which to influence firms' performance outcomes. We present the analyzed paths in Figure 2 and deliberate about this in more detail in the Discussion and conclusion section.

\begin{tabular}{lcccccc}
\hline SO & INNO & CS & ADAPT & FP & \multicolumn{2}{c}{ Hypotheses Testing } \\
\hline CO & $0.38^{*}(4.83)$ & - & - & - & $H 1$ & Supported \\
PO & $0.35^{*}(3.64)$ & - & - & - & $H 2$ & Supported \\
TO & $0.28^{*}(3.32)$ & - & - & - & $H 3$ & Supported \\
IO & $0.01(0.09)$ & - & - & - & $H 4$ & Not supported \\
INNO & - & $0.83^{*}(10.01)$ & $0.60^{*}(9.15)$ & - & $H 5 a, H 6 a$ & Supported \\
CS & - & - & - & $0.31^{*}(3.79)$ & $H 5 b$ & Supported \\
ADAPT & - & - & - & $0.52^{*}(6.00)$ & $H 6 b$ & Supported
\end{tabular}

$\chi^{2}=616.012$; degrees of freedom $=336$

Table I.

Notes: $\mathrm{SO}=$ Strategic orientations; $\mathrm{RMR}=0.120 ; \mathrm{RMSEA}=0.069 ; \mathrm{GFI}=0.880 ; \mathrm{NFI}=0.930 ; \mathrm{CFI}=$ The results of model $0.943 ; *=\beta$ coefficients are significant $(p<0.01)$; the number in parenthesis $=t$ value 
APJIE

10,1

\section{4}

Figure 2.

The analyses of alternative models
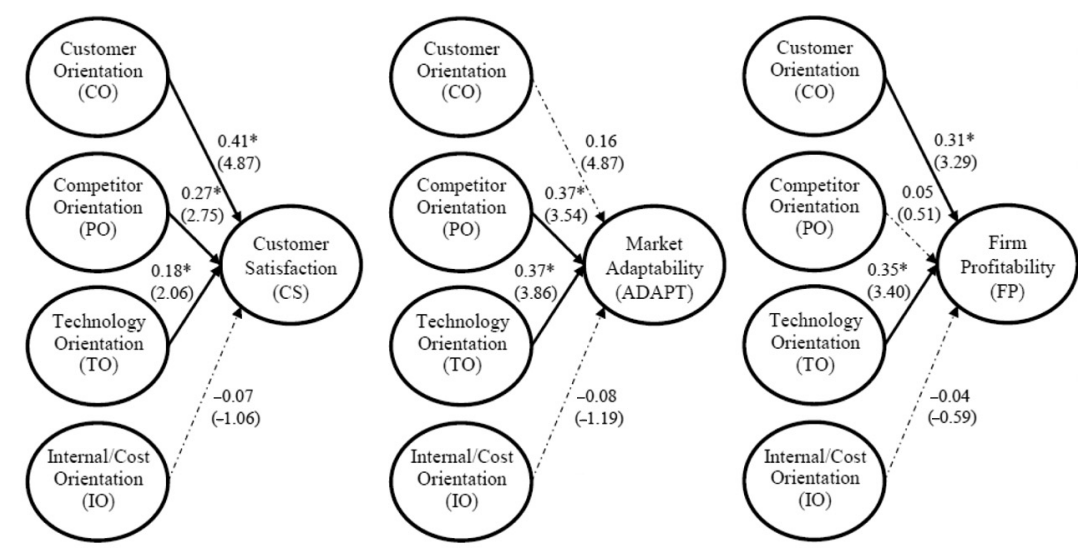

\begin{tabular}{lll}
\hline Chi-Square $=303.462 ;$ D.F. $=142$ & Chi-Square $=285.628 ;$ D.F. $=125$ & Chi-Square $=269.493 ;$ D.F. $=125$ \\
RMR $=0.09 ;$ RMSEA $=0.05 ;$ & RMR $=0.10 ;$ RMSEA $=0.08 ;$ & RMR $=0.08 ;$ RMSEA $=0.04 ;$ \\
GFI $=0.916 ;$ NFI $=0.936 ;$ CFI $=$ & GFI $=0.899 ;$ NFI $=0.923 ;$ CFI $=$ & GFI $=0.922 ;$ NFI $=0.941 ;$ CFI $=$ \\
0.951 & 0.944 & 0.964
\end{tabular}

Notes: ${ }^{*}=\beta$ coefficients are significant $(p<0.01)$; the number in parenthesis $=t$-value

\section{Discussion and conclusion}

\subsection{Summary and conceptual implications}

This study delivers several meaningful substantive contributions. First, we show the finding that INNO affects FP through CS and ADAPT, confirming the theoretical logic of the routes, i.e. from INNO through market position (CS, ADAPT) to financial position (Rubera and Kirca, 2012). Next, our finding suggests that strategic orientations CO, PO and TO influence INNO, leading to better business performance, whereas IO shows no effect on INNO. This might mean that market-driven and market-driving innovations (CO and TO) which seek for unique solutions to meet customer needs and preemptive actions against major competitors (PO) overweigh cost-driven innovations (Jaworski and Sahay, 2000; Kumar et al., 2000; Narver et al., 2004). In other words, our study findings imply the possibility that the differentiation strategy route fits well with INNO culture, as opposed to the low-cost strategy route (Porter, 1985)[1]. Third, interestingly, ADAPT links to FP more strongly than CS; yet, the relationship between INNO and CS is stronger than INNO and ADAPT. This could be interpreted such that INNO is related to CS more strongly than to ADAPT, yet FP is more generated by ADAPT than CS. In other words, for INNO to relate to firm profitability, firms had to better note the necessary condition that INNO brings about CS and the sufficient condition that INNO fits with ever-changing market needs.

Moreover, it was found that the respective strategic antecedents may have very different paths to organizational performances (Figures 2 and 3). CO does not have a direct relationship with ADAPT, and PO shows no direct link to FP, in which the mediating roles of INNO are important. This result is consistent with Han et al.'s (1998) finding that innovation plays a mediating role in the effect of market orientation and organizational performance. Meanwhile, TO shows not only an indirect impact on FP through INNO but also direct relationships with all performance outcomes: CS, ADPT 


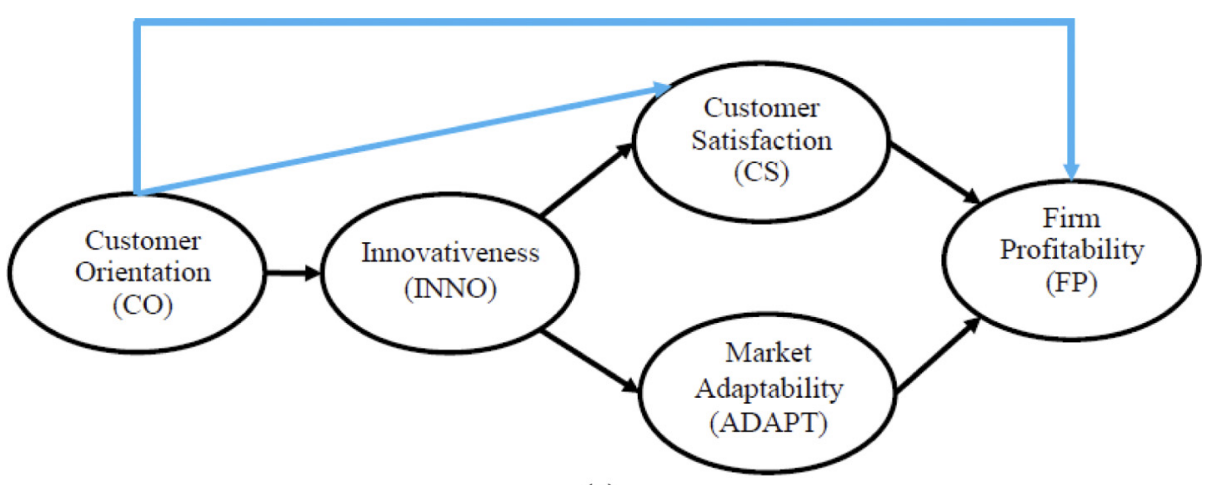

Large Korean

companies

(a)

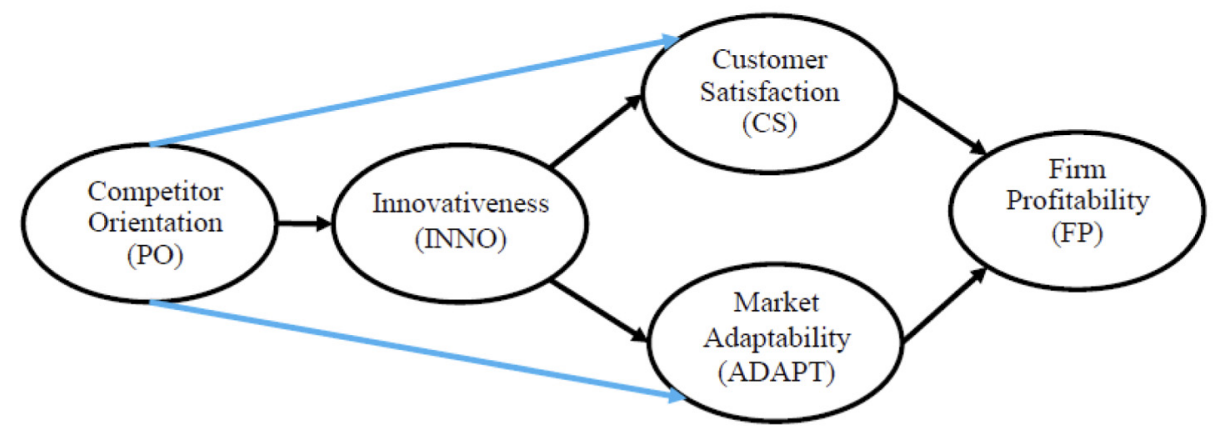

(b)

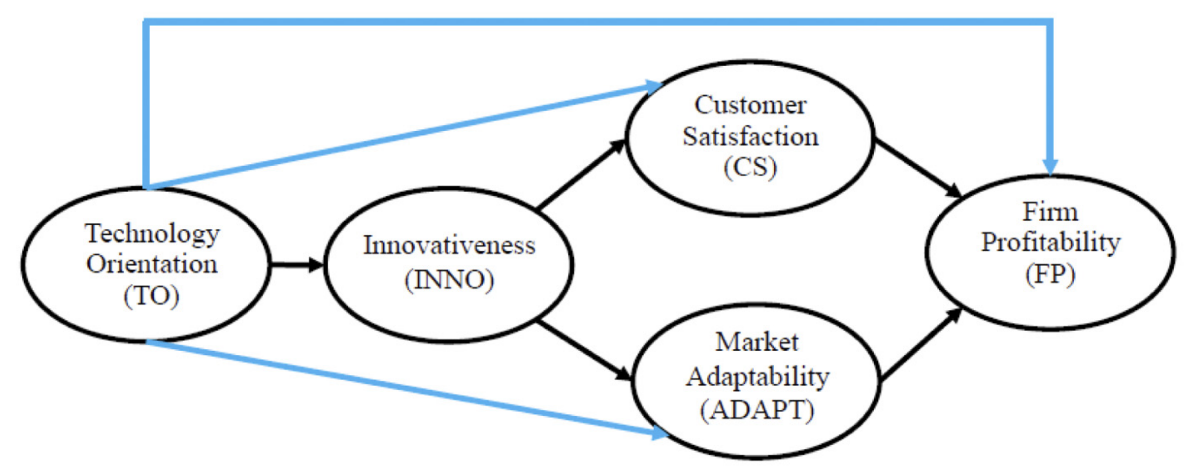

(c)

Notes: (a) The significant paths of $\mathrm{CO}$; (b) the significant paths of $\mathrm{PO}$; (c) the significant paths of TO

Figure 3. The mediation analyses of significant paths 

between firms' strategic orientations and organizational performances. For example, TO may be construed as a fundamental orientation required of firms; CO may be facilitated to guide firms' efforts of INNO from the perspective of providing value for customers, and PO may induce firms' INNO efforts from the perspective of providing value for firms. In other words, multiple orientations may be needed for firms in achieving superior competitive advantage (performance) in a modern environment of ever-intensifying competition, which needs to be further explored in future research.

Regarding the role of IO with respect to INNO, it is worth taking a careful reasoning on why one of important organizational orientations, i.e. IO, does not turn out to have a significant relationship with INNO. The plausible reason for this result might be that both positive and negative effects get balanced out, showing no effect. That is, we may miss out some important moderators or mediators in the relationship between IO and INNO. Further research requires more systematic inquiry of the deeper nature of this relationship. For example, as indicated in our conceptualization, organizational characteristics such as centralized/decentralized decision-making or formal/informal structure may moderate the effect of IO on INNO. The centralized decision-making and/or formal structure could lead to negative effect of IO on INNO, as the organization is likely to control costs as much as possible by pursuing standardized practices (Ruekert et al., 1985; Walker and Ruekert, 1987). On the other hand, decentralized decision-making and/or informal structure is more likely to result in a positive effect of IO on INNO, mainly because the organization may put an emphasis on utilizing creative and new approaches to efficiency (Treacy and Wiersema, 1993). Instead of examining the moderating roles of organizational characteristics in the effect of IO on INNO, the construct of IO per se could be divided into two distinct constructs: "smart" IO which emphasizes on creative method of cost reduction and "ordinary" IO which stresses on continuous standardization efforts[2]. As a matter of fact, Rubera and Kirca (2012) implied a similar viewpoint regarding the positive relationship between "smart" IO and INNO. But, this relationship was shown by the existence of the reverse causal relationship. Specifically, in the context of our study, it may be very plausible for managers to argue that INNO leads to the development of internal capabilities that help firm reduce the costs of operation: the route from INNO to "smart" IO (Geroski et al., 1993; McGrath et al., 1996). This possibility highlights the future research to consider a longitudinal study instead of a cross-sectional study to dive deep into the relationship between IO and INNO.

\subsection{Managerial implications}

The results of our study provide a few insights to marketing and management executives who are in search for a way out from harsh competitive environments. First, a company has to better understand how its orientations of $\mathrm{CO}, \mathrm{PO}, \mathrm{TO}$ and IO can ultimately affect its performance outcomes. It is very important not only to have a shared understanding of the firm's strategic orientations but also to possess the INNO culture leading to the "real" capacity to innovate. On the one hand, $\mathrm{CO}, \mathrm{PO}$ and TO need to be cultivated, linking to the firm's INNO culture. On the other hand, the INNO culture can be developed by making the organizational members engage and see the tangible outcomes, such as new products or services, which link to firms' profitability. 
Further, it is critical to understand that three essential strategic orientations, namely, $\mathrm{CO}, \mathrm{PO}$ and TO, have different impacts on the firm's INNO culture and its performance outcomes. To obtain better FP efficiently, companies may need multiple orientations, for example, TO, first, and then $\mathrm{CO}$ and $\mathrm{PO}$. Moreover, when we regard these orientations as resources to be obtained and/or developed, depending on which objective a firm chases, specific paths of development can be selected. For example, when CS is an objective of high priority, the firm may efficiently obtain its goal by focusing on enhancing $\mathrm{CO}$ along with the INNO culture. As an additional example, when ADAPT is the most critical end, $\mathrm{PO}$ and TO have to be better operated. Hence, some possible answers can be provided to executive-level managers in terms of which strategic orientations could be emphasized on along with related routines and activities for the firm to obtain and sustain "above-the-normal" performance outcomes (refer to Figure 3 for all possible systematic paths for each predictor orientation).

\subsection{Limitations and future research directions}

Despite the insights gained, there are several limitations of the study. The first reflects the issues of external validity, namely, the ability to generalize the results outside of this study context. Another limitation is that this research is conducted with the survey responses provided by one key informant per firm or strategic business unit. Although such an approach has long been used in strategy research (Hult et al. 2005) because of the constraint of research resources, using multiple informants might be recommended for further research.

Additional future studies might take some of the following directions. First, it would be valuable to use the objective measures of FP, such as revenues, profits, return on investment (ROI), Tobin's $q$, etc. Second, as explained in the Introduction, the other types of INNO constructs, such as INNO inputs and INNO outputs, may be examined along with the relevant antecedents and consequences. Third, as discussed, the possible moderators or mediators in the relationship of IO and INNO have to be better explored, including the reverse causal relationship between INNO and IO with a longitudinal study. Last, as explained by additional analyses, it may well be needed to more thoroughly conceptualize and empirically test multiple roles of the firm's strategic orientations in driving INNO and performance outcomes, focusing on the respective paths from important strategic orientations.

\subsection{Conclusions}

On the basis of systematic review of diverse literature on innovation, our study is initiated, focusing on three research needs:

(1) The systematic and hierarchical relationships among firms' strategic orientations and INNO may well be studied.

(2) It is meaningful to investigate firms' alternative strategic orientations, as comprehensively as possible, as the drivers of INNO.

(3) It would be necessary to examine the effects of firms' strategic orientations on INNO in Eastern countries.

The major question addressed whether each of key strategic orientations, such as $\mathrm{CO}, \mathrm{PO}$, TO and IO, is related to INNO culture and firm performance in Eastern country such as Korea. In general, our study appears to achieve our research 

INNO and its performance outcomes in large Korean companies. It highlights the importance of not only the firm's INNO culture in driving its performance outcomes but also the specific strategic orientations desirable to cultivate the firm's INNO culture such as CO, PO and TO in large Korean companies, which corroborate the importance of INNO in the literature, and extend the generalizability of the importance of INNO to Eastern countries. Our study findings confirm the empirical finding that the relationship between INNO and its performance outcomes is not different between the firms of Western countries and those of Eastern companies (Rhee et al., 2010; Rubera and Kirca, 2012; Zhou et al., 2005). Specifically, compared to Zhou et al.'s (2005) analysis of Chinese companies and Rhee et al.'s (2010) inquiry of Korean small- and medium-sized companies, our study finds the positive relationship between INNO and firm performance in the context of relatively large Korean companies. Last, this research contributes to the INNO literature by uniquely showing the hierarchical relationships between companies' more abstract strategic culture such as CO, PO and TO and their more specific INNO culture.

\section{Notes}

1. We reckon that it is premature and risky to strongly assert this possibility with just one empirical study. Further discussion of the relationship between the low-cost strategy route and INNO is presented in the part of 5.1.

2. We appreciate a reviewer's suggestion of this possibility.

\section{References}

Abratt, R. and Lombard, A.V.A. (1993), "Determinants of product innovation in speciality chemical companies”, Industrial Marketing Management, Vol. 22 No. 3, pp. 169-175.

Agarwal, S.M., Erramilli, K. and Dev, C.S. (2003), "Market orientation and performance in service firms: role of innovation”, Journal of Services Marketing, Vol. 17 No. 1, pp. 68-82.

Alberts, W. (1989), “The experience curve doctrine reconsidered”, Journal of Marketing, Vol. 53 No. 3, pp. 36-49.

Armstrong, J.S. and Overton, T.S. (1977), "Estimating nonresponse bias in mail surveys”, Journal of Marketing Research, Vol. 14 No. 3, pp. 396-402.

Anderson, E.W., Fornell, C. and Lehmann, D.R. (1994), "Satisfaction, market share, and profitability: findings from Sweden”, Journal of Marketing, Vol. 58 No. 3, pp. 53-66.

Atuahene-Gima, K. (1996), "Market orientation and innovation”, Journal of Business Research, Vol. 35 No. 2, pp. 93-103.

Bagozzi, R.P. and Yi, Y. (1988), "On the evaluation of structural equation models”, Journal of the Academy of Marketing Science, Vol. 16 No. 1, pp. 74-94.

Calantone, R.J., Cavusgil, S.T. and Zhao, Y. (2002), "Learning orientation, firm innovation capability, and firm performance”, Industrial Marketing Management, Vol. 31 No. 6, pp. 515-524.

Christensen, C.M. and Bower, J.L. (1996), "Customer power, strategic investment, and the failure of leading firms”, Strategic Management Journal, Vol. 17 No. 3, pp. 197-218.

Cooper, R.G. (1985), “Overall corporate strategies for new product programs”, Industrial Marketing Management, Vol. 14 No. 3, pp. 179-193. 
Cooper, R.G. and Kleinschmidt, E.J. (1994), "Determinants of timeliness in product development", Journal of Product Innovation Management, Vol. 11 No. 5, pp. 381-396.

Damanpour,F. (1991), "Organizational innovations: a meta-analysis of effects of determinants and moderators”, Academy of Management Journal, Vol. 34 No. 3, pp. 555-591.

Day, G.S. (1994), “The capabilities of market-driven organizations”, Journal of Marketing, Vol. 58 No. 4, pp. 37-52.

Day, G.S. and Nedungadi, P. (1994), "Managerial representations of competitive advantage", Journal of Marketing, Vol. 58 No. 2, pp. 31-44.

Day, G.S. and Wensley, R. (1988), “Assessing advantage: a framework for diagnosing competitive superiority”, Journal of Marketing, Vol. 52 No. 2, pp. 1-20.

Deshpande, R., Farley, J.U. and Webster, F.E., Jr (1993), "Corporate culture, customer orientation, and innovativeness in Japanese firms: a quadrad analysis", Journal of Marketing, Vol. 57 No. 1, pp. 23-37.

Fornell, C. (1992), "A national customer satisfaction barometer: the Swedish experience”, Journal of Marketing, Vol. 56 No. 1, pp. 6-21.

Fornell, C., Johnson, M.D., Anderson, E.W., Cha, J.S. and Bryant, B.E. (1996), "The American customer satisfaction index: nature, purpose, and findings", Journal of Marketing, Vol. 60 No. 4, pp. 7-18.

Gatignon, H. and Xuereb, J.M. (1997), "Strategic orientation of the firm and new product performance”, Journal of Marketing Research, Vol. 34 No. 1, pp. 77-90.

Geroski, P.A., Machin, S. and Reenan, J.V. (1993), "The profitability of innovating firms”, RAND Journal of Economics, Vol. 24 No. 2, pp. 198-212.

Grinstein, A. (2008), "The relationships between market orientation and alternative strategic orientations: a meta-analysis”, European Journal of Marketing, Vol. 42 Nos 1/2, pp. 115-134.

Gruca, T.S. and Rego, L.L. (2005), "Customer satisfaction, cash flow, and shareholder value", Journal of Marketing, Vol. 69 No. 3, pp. 115-130.

Han, J.K., Kim, N. and Srivastava, R.K. (1998), "Market orientation and organizational performance: is innovation a missing link", Journal of Marketing, Vol. 62 No. 4, pp. 30-45.

Hauser, J., Tellis, G. and Griffin, A. (2006), "Research on innovation and new products: a review and agenda for marketing science”, Marketing Science, Vol. 25 No. 6, pp. 687-717.

Henard, D.H. and Szymanski, D.M. (2001), "Why some new products are more successful than others”, Journal of Marketing Research, Vol. 38 No. 3, pp. 362-375.

Homburg, C., Workman, J.P. and Krohmer, H. (1999), "Marketing's influence within the firm", Journal of Marketing, Vol. 63 No. 2, pp. 1-17.

Hoover, W.E., Jr, Elorante, E., Holmström, J. and Huttunen, K. (2001), Managing the Demand-Supply Chain: Value Innovations for Customer Satisfaction, John Wiley \& Sons, New York.

Hult, G.T.M. and Ketchen, D.J., Jr (2001), "Does market orientation matter? A test of the relationship between positional advantage and performance", Strategic Management Journal, Vol. 22 No. 9, pp. 899-906.

Hult, G.T.M., Hurley, R.F. and Knight, G.A. (2004), "Innovativeness: its antecedents and impact on business performance”, Industrial Marketing Management, Vol. 33 No. 5, pp. 429-438. 
APJIE

10,1

Hult, G.T.M., Ketchen, D.J., Jr and Slater, Stanley, F. (2005), “Market orientation and performance: an integration of disparate approaches", Strategic Management Journal, Vol. 26 No. 12, pp. 1173-1181.

Hurley, R.F. and Hult, G.T.M. (1998), "Innovation, market orientation, and organizational learning: an integration and empirical examination”, Journal of Marketing, Vol. 62 No. 3, pp. 42-54.

Jaworski, B.J. and Kohli, A.K. (1993), "Market orientation: antecedents and consequences”, Journal of Marketing, Vol. 57 No. 3, pp. 53-70.

Jaworski, B.J. and Sahay, A. (2000), "Market-driven versus driving markets", Journal of the Academy of Marketing Science, Vol. 28 No. 1, pp. 45-54.

Kaplan, R.S. and Norton, D.P. (1996), "Using the balanced scorecard as a strategic management system”, Harvard Business Review, Vol. 74 No. 1, pp. 37-48.

Kirca, A.H., Jayachandran, S. and Bearden, W.O. (2005), "Market orientation: a meta-analytic review and assessment of its antecedents and impact on performance", Journal of Marketing, Vol. 69 No. 2, pp. 24-41.

Kohli, A.K. and Jaworski, B.J. (1990), "Market orientation: the construct, research propositions, and managerial implications", Journal of Marketing, Vol. 54 No. 2, pp. 1-18.

Kumar, N., Scheer, L. and Kotler, P. (2000), "From market driven to market driving”, European Management Journal, Vol. 18 No. 2, pp. 129-142.

Lee, S., Yoon, S.J., Kim, S. and Kang, J.W. (2006), “The integrated effects of market-oriented culture and marketing strategy on firm performance", Journal of Strategic Marketing, Vol. 14 No. 3, pp. 245-261.

Lukas, B.A. and Ferrell, O.C. (2000), "The effect of market orientation on product innovation", Journal of the Academy of Marketing Science, Vol. 28 No. 2, pp. 239-247.

McGrath, Rita, G., Tsai, Ming-Hone, Venkataraman, S. and MacMillan, I.C. (1996), "Innovation, competitive advantage, and rent: a model and test”, Management Science, Vol. 42 No. 3, pp. 389-403.

March, J.G. (1991), "Exploration and exploitation in organizational learning", Organization Science, Vol. 2 No. 1, pp. 71-87.

Menguç, B. and Auh, S. (2006), "Creating a firm-level dynamic capability through capitalizing on market orientation and innovativeness", Journal of the Academy of Marketing Science, Vol. 34 No. 1, pp. 63-73.

Montoya-Weiss, M.M. and Calantone, R. (1994), "Determinants of new product performance: a review and meta-analysis", Journal of Product Innovation Management, Vol. 11 No. 5, pp. 397-417.

Morgan, N.A., Clark, B.H. and Gooner, R.A. (2002), "Marketing productivity, marketing audits, and systems for marketing performance assessment: integrating multiple perspectives", Journal of Business Research, Vol. 55 No. 5, pp. 363-375.

Morgan, N.A., Clark, B.H. and Rego, L.L. (2006), "The value of different customer satisfaction and loyalty metrics in predicting business performance", Marketing Science, Vol. 25 No. 5, pp. 426-439.

Morgan, N.A., Clark, B.H., Zou, S., Vorhies, D.W. and Katsikeas, C.S. (2003), "Experiential and informational knowledge, architectural marketing capabilities, and the adaptive performance of export ventures: a cross-national study", Decision Sciences, Vol. 34 No. 2, pp. 287-321.

Naman, J.L. and Slevin, D.P. (1993), "Entrepreneurship and the concept of fit: a model and empirical tests", Strategic Management Journal, Vol. 14 No. 2, pp. 137-153. 
Narver, J.C. and Slater, S.F. (1990), "The effect of a market orientation on business profitability", Journal of Marketing, Vol. 54 No. 4, pp. 20-35.

Narver, J.C., Slater, S.F. and MacLachlan, D.L. (2004), "Responsive and proactive market orientation and new-product success", Journal of Product Innovation Management, Vol. 21 No. 5, pp. 334-347.

Noble, C.H., Sinha, R.K. and Kumar, A. (2002), "Market orientation and alternative strategic orientations: a longitudinal assessment of performance implications", Journal of Marketing, Vol. 66 No. 4, pp. 25-39.

Nunnally, J.C. (1978), Psychometric Methods, McGraw Hill, New York.

Olson, E.M., Slater, S.F. and Hult, G.T. (2005), "The performance implications of fit among business strategy, marketing organization structure, and strategic behavior", Journal of Marketing, Vol. 69 No. 3, pp. 49-65.

Olson, E.M., Slater, S.F. and Hult, G.T., Walker, O.C., Jr, Ruekert, R.W. and Bonner, J.M. (2001), "Patterns of cooperation during new product development among marketing, operations and R\&D: implications for project performance", Journal of Product Innovation Management, Vol. 18 No. 4, pp. 258-271.

Podsakoff, P.M. and Organ, D.W. (1986), "Self-reports in organizational research: problems and prospects", Journal of Management, Vol. 12 No. 4, pp. 531-544.

Podsakoff, P.M., Organ, D.W., MacKenzie, S.B., Lee, J.Y. and Podsakoff, N.P. (2003), “Common method biases in behavioral research: a critical review of the literature and recommended remedies", Journal of Applied Psychology, Vol. 88 No. 5, pp. 879-903.

Poolton, J. and Barclay, I. (1998), "New product development from past research to future applications", Industrial Marketing Management, Vol. 27 No. 3, pp. 197-212.

Porter, M.E. (1985), Competitive Strategy, The Free Press, New York, NY.

Porter, M.E. (1990), “The competitive advantage of nations”, Harvard Business Review, Vol. 68 No. 2, pp. 73-91.

Rhee, J., Park, T. and Lee, D.H. (2010), "Drivers of innovativeness and performance for innovative SMEs in South Korea: mediation of learning orientation", Technovation, Vol. 30 No. 1, pp. 65-75.

Ruekert, R.W., Walker, O.C. and Roering, K.J. (1985), “The organization of marketing activities: a contingency theory of structure and performance", Journal of Marketing, Vol. 49 No. 1, pp. 13-25.

Rubera, G. and Kirca, A.H. (2012), "Firm innovativeness and its performance outcomes: a meta-analytic review and theoretical integration", Journal of Marketing, Vol. 76 No. 3, pp. 130-147.

Shane, S.A. and Ulrich, K.T. (2004), "Technological innovation, product development, entrepreneurship in management science”, Management Science, Vol. 50 No. 2, pp. 133-145.

Slater, S.F. and Narver, J.C. (1998), “Customer-led and market-oriented: let's not confuse the two", Strategic Management Journal, Vol. 19 No. 10, pp. 1001-1006.

Song, M.X. and Parry, M.E. (1997), "A cross-national comparative study of new product development processes: Japan and the United States", Journal of Marketing, Vol. 61 No. 2, pp. 1-18.

Szymanski, D.M., Kroff, M.W. and Troy, L.C. (2007), "Innovativeness and new product success: insights from cumulative evidence", Journal of the Academy of Marketing Science, Vol. 35 No. 1, pp. 35-44. 
APJIE

10,1

Tajeddini, K., Trueman, M. and Larsen, G. (2006), "Examining the effect of market orientation on innovativeness", Journal of Marketing Management, Vol. 22 Nos 5/6, pp. 529-551.

Tellis, G.J., Prabhu, J.C. and Chandy, R.K. (2009), "Radical innovation across nations: the preeminence of corporate culture", Journal of Marketing, Vol. 73 No. 1, pp. 3-23.

Treacy, M. and Wiersema, F. (1993), "Customer intimacy and other value disciplines", Harvard Business Review, Vol. 71 No. 1, pp. 84-93.

Vorhies, D.W. and Morgan, N.A. (2005), "Benchmarking marketing capabilities for sustainable competitive advantage”, Journal of Marketing, Vol. 69 No. 1, pp. 80-94.

Vorhies, D.W., Harker, M. and Rao, C.P. (1999), “The capabilities and performance advantages of market-driven firms", European Journal of Marketing, Vol. 33 Nos 11/12, pp. 1171-1202.

Voss, G.B. and Voss, Z.G. (2000), "Strategic orientation and firm performance in an artistic environment”, Journal of Marketing, Vol. 64 No. 1, pp. 67-83.

Walker, O.C. and Ruekert, R.W. (1987), "Marketing's role in the implementation of business strategies: a critical review and conceptual framework", Journal of Marketing, Vol. 51 No. 3, pp. 15-33.

Walker, R. (2004), "Innovation and organizational performance: evidence and research agenda”, Advance Institute of Management Research Working Paper Series 1744-0009, pp. 1-55.

Wernerfelt, B. (1984), “A resource-based view of the firm”, Strategic Management Journal, Vol. 5 No. 2, pp. 171-180.

Woodside, A.G. (2005), "Firm orientations, innovativeness, and business performance: advancing a system dynamics view following a comment on Hult, Hurley, and Knight's 2004 study", Industrial Marketing Management, Vol. 34 No. 3, pp. 275-279.

Zhou, K.Z., Yim, C.K. and Tse, D.K. (2005), "The effects of strategic orientations on technology and market-based breakthrough innovations", Journal of Marketing, Vol. 69 No. 2, pp. 42-60.

\section{Corresponding author}

Sungho Lee can be contacted at: shlee@uos.ac.kr

For instructions on how to order reprints of this article, please visit our website:

www.emeraldgrouppublishing.com/licensing/reprints.htm

Or contact us for further details: permissions@emeraldinsight.com 